\title{
Screening of Industrial Wastewaters as Feedstock for the Microbial Production of Oils for Biodiesel Production and High-Quality Pigments
}

\author{
Teresa Schneider, ${ }^{1}$ Simone Graeff-Hönninger, ${ }^{1}$ William Todd French, ${ }^{2}$ Rafael Hernandez, ${ }^{2}$ \\ Wilhelm Claupein, ${ }^{1}$ William E. Holmes, ${ }^{2}$ and Nikolaus Merkt ${ }^{1}$
}

${ }^{1}$ Crop Science, Universität Hohenheim, Fruwirthstraße 23, 70599 Stuttgart-Hohenheim, Germany

${ }^{2}$ Dave C. Swalm School of Chemical Engineering, Mississippi State University, Starkville P.O. Box 9595, MS 39762, USA

Correspondence should be addressed to Teresa Schneider, teresa.schneider@uni-hohenheim.de

Received 1 November 2011; Revised 26 January 2012; Accepted 1 February 2012

Academic Editor: Panagiotis Grammelis

Copyright ( $) 2012$ Teresa Schneider et al. This is an open access article distributed under the Creative Commons Attribution License, which permits unrestricted use, distribution, and reproduction in any medium, provided the original work is properly cited.

\begin{abstract}
The production of biodiesel has notably increased over the past decade. Currently, plant oil is the main feedstock for biodiesel production, but, due to concerns related to the competition with food production, alternative oil feedstocks have to be found. Oleaginous yeasts are known to produce high amounts of lipids, but no integrated process from microbial fermentation to final biodiesel production has reached commercial realization yet due to economic constraints. Therefore, growth and lipid production of red yeast Rhodotorula glutinis was tested on low-cost substrates, namely, wastewaters from potato, fruit juice, and lettuce processing. Additionally, the production of carotenoids as high-value by-products was examined. All evaluated wastewaters met the general criteria for microbial lipid production. However, no significant increase in lipid content was observed, probably due to lack of available carbon in wastewaters from fruit juice and lettuce processing, and excess of available nitrogen in potato processing wastewater, respectively. During growth on wastewaters from fruit juice and lettuce processing the carotenoid content increased significantly in the first 48 hours. The relations between carbon content, nitrogen content, and carotenoid production need to be further assessed. For economic viability, lipid and carotenoid production needs to be increased significantly. The screening of feedstocks should be extended to other wastewaters.
\end{abstract}

\section{Introduction}

In the course of the ongoing endeavor to find alternatives for fossil energy, significant effort has been put into expanding the utilization of renewable resources. Accordingly, there is already a considerable variety of products and commodities based on renewable resources available, which are fed both into energetic and material utilization pathways. Especially in the field of energy supply, the progressive depletion of conventional fossil fuels along with a worldwide growing demand for petroleum-based fuels has put high pressure on science and industry to find alternative energy sources [1]. Over the last decade, research has successfully managed to develop a broad range of sustainable and cost-effective techniques to produce renewable energy, one of them being the conversion of biomass into biofuels. While biofuels in general also include, for example, firewood or woodchips for direct combustion and use for heating or electricity production, liquid biofuels are mainly researched in order to replace conventional liquid fuels like diesel and petroleum [1].

Within this class, biodiesel is a renewable fuel, which is produced through the transesterification of oils to generate fatty acid methyl/ethyl esters (FAME/FAEE) [2]. Depending on the origin of the oily feedstock, it is referred to as 1 st generation, 2 nd generation, or meantime 3 rd generation biodiesel.

While 1st generation biodiesel uses plant oils from for example, rapeseed and soybean for transesterification, 2nd generation biodiesel is derived from, lignocellulosic biomass that underlies biological or thermochemical processing thus increasing the land use efficiency [1]. Nevertheless, both approaches amplify the highly discussed competition with 
food production either due to the direct use of edible crops for energetic purposes thus causing worldwide rising commodity prices, or because of shifting high-quality agricultural land away from food production to the cultivation of crops for energy production [3]. Biodiesel production of the 3rd generation tries to overcome this conflict by using fatty acids produced by oleaginous microorganisms for the transesterification into the FAMEs/FAEEs. In general, microorganisms that accumulate more than $20-25 \%$ of their cell dry weight in the form of lipids are referred to as oleaginous species [4], which include different types of yeast, molds, and algae. Especially the use of oleaginous yeast is a promising approach since they stand out from other heterotrophic microorganisms in terms of fast growth rate and high lipid content $[3,5,6]$. In addition, their lipids are mainly composed of triacylglycerols, which make their chemical characteristics and thus the potential applications comparable to plant oil [3]. Further advantages of yeasts compared to other microorganisms like fungi or microalgae include the low duplication times and the more easily scale up [5]. Commercial oil production using autotrophic algae, for example, might be restricted due to the need for sunlight during the cultivation process $[1,6]$.

The idea to use oleaginous yeast as source for microbial oil is not new [4]. Also, the various advantages over plants for the production of lipids such as short life cycles, low demand on space and independence of location, season, and climate $[3,5]$ have been widely recognized. Nevertheless, so far hardly any approach reached commercial realization, because the economics of production cannot compete yet with the comparable low costs of agricultural plant oil production [4]. Moreover, the comparatively costly process of microbial oil production and extraction results in biodiesel, which is considered as a rather low-value product. However, in the last years, interest in microbial oil production increased again due to the serious need for feedstock alternatives and biotechnological progress regarding the efficiency and scale up of the process of lipid production, extraction, and conversion to the desired FAMEs/FAEEs. Still, in order to reach economic feasibility, it is unavoidable to find low-cost and abundant feedstocks as well as low-cost and efficient extraction methods for microbial oil production.

The biochemical pathway of lipid accumulation in oleaginous yeasts is a secondary anabolic activity, which takes place under the preconditions of nitrogen depletion and carbon excess conditions in the culture medium, leading to a "metabolic overflow," where products from carbon degradation are not channeled into cell growth due to the lacking nitrogen, but into the synthesis of cellular storage lipids [7]. Regarding the characteristics of the carbon source, yeasts have only few requirements [6]. Consequently, they can utilize a broad range of substrates ranging from monosaccharides like glucose and xylose and polysaccharides like starch over cellulose hydrolysates to industrial and municipal organic waste with the latter fulfilling the criteria of cheap and vast availability [3]. Against this background, a variety of fermentation substrates have been tested for their ability to serve oleaginous yeast as adequate growth and production media, including, for example, effluent from steam fish processing [8], whey [9], municipal wastewater and sewage sludge [10-12], lignocellulosic materials [13], molasses [1416], glycerol [17], and starch wastewater [18].

Still these feedstocks, even if renewable and abundant, have some negative aspects. Agricultural by-products like molasses from sugar beet and sugarcane can be used for other purposes like animal feed, thus resulting in a certain conflict of utilization. Other substrates like hydrolysates from lignocellulosic materials require a treatment prior to fermentation thus causing additional cost. That is why this paper looks at substrates-namely, wastewaters from food and beverage industry with a supposable high organic load-that have no alternative utilization and generally do not need an additional pretreatment.

In addition, the fermentation process with the microorganisms could possibly be included in an already existing wastewater treatment process, thus leading to a decrease in both chemical (COD) and biological oxygen demand (BOD) of the wastewater, bearing an additional cost-saving potential $[8,11,18]$.

In order to reach the economic feasibility of microbial biodiesel production, the marketing of higher added value products that are formed in the course of microbial fermentation of the feedstock is another option. Depending on the substrate and microorganism used, this can be, for example, specialty chemicals, biosurfactants, or certain pigments. The red yeast Rhodotorula glutinis is a very efficient oleaginous yeast, that is able to accumulate up to $70 \%$ of its cell dry weight in the form of lipids [19] with a biomass production up to $180 \mathrm{~g} \mathrm{~L}^{-1}$ in rich fermentation media [20]. Additionally the fatty acid profile is rich in palmitic, oleic, and linolenic acid [21] and therefore comparable to vegetable oils allowing for biodiesel production. In addition, it is comparatively unproblematic to handle, being nontoxic and easy to grow and harvest [16]. Furthermore, Rhodotorula glutinis is able to produce certain carotenoids, namely, $\beta$-carotene, torularhodin, and torulene [22]. Especially, $\beta$-carotene, displaying an orange-yellow color, is commercially used as a natural colorant in food, feed, and cosmetic industry and, being the main source of provitamin A, as nutritional supplement [23]. It also finds application in the pharmaceuticals industry due to the ability to act as antioxidant and anticancer agent [24]. The production of carotenoids by Rhodotorula glutinis has also already been tested on a broad range of different waste and residue substrates including radish brine [24], whey [25], molasses, grape must, and different flour extracts [26]. Based on numbers of the Brazilian market, $1 \mathrm{~kg}$ of pure $\beta$ carotene corresponds to US $\$ 600$, making it a high-value product [23]. The natural production of carotenoids via microorganisms also takes into account the shift in consumer preferences from synthetically produced towards naturally produced food additives [27].

This shows that the economic restrictions regarding the application of microbial oils as renewable resource for biodiesel production can be overcome by the use of a cheap feedstock and the production of two products including a high value pigment. Since pigments will mostly be used for applications in the food and cosmetic sector, feedstocks like municipal wastewater or sewage sludge, which hold the same 
economic advantages as wastewaters from food and beverage processing, have to be ruled out since the mentioned products could hardly be marketed if they are derived from human or animal waste.

In order to combine the production of biodiesel with In order to combine the production of biodiesel with the production of carotenoids as high value by-product and with the utilization of a cheap and abundant carbon source, the goal of this study was to examine cell growth, lipid and carotenoid production of Rhodotorula glutinis grown on wastewaters from fruit juice production, potato processing, and lettuce processing.

\section{Materials and Methods}

2.1. Wastewater. Three different process wastewaters were tested as growth substrate for Rhodotorula glutinis. Samples of potato process water were taken from a potato processing company directly after mechanical peeling. Wastewater from lettuce processing was collected after the processing steps of washing and cutting. Samples of fruit juice processing wastewater, mostly from apple processing, were obtained from a small fruit juice producer. This wastewater included all process waters from washing and pressing as well as any runoff water within the production. Chemical oxygen demand (COD) and total nitrogen content $\left(\mathrm{N}_{t}\right)$ were determined photometrically using reagent vials from Macherey-Nagel (Düren, Germany). For COD measurement, $2 \mathrm{~mL}$ of wastewater were added to the vials and digested for $2 \mathrm{~h}$. COD values were then determined using a spectrophotometer (NANOCOLOR 400D; Macherey-Nagel, Düren, Germany) operated at $620 \mathrm{~nm}$. Total nitrogen was determined according to DIN EN ISO 11905-1 using a wavelength of $385 \mathrm{~nm}$. pH was measured potentiometrically using a $\mathrm{pH}$-meter with glass electrode (SenTix 61, WTW GmbH, Weilheim, Germany) (Table 1). For the determination of lipid production, all wastewaters were sterile filtered prior to inoculation in order to maintain Rhodotorula glutinis as only microorganism. The potato wastewater had an initial high starch content, which decreased after sterile filtration. Therefore, $100 \mathrm{mg} \mathrm{L}^{-1}$ soluble starch was added to the wastewater according to the difference in starch content prior and after filtration.

2.2. Microorganism, Cultivation, and Analysis. R. glutinis (CBS 20) from the collection of the Centraalbureau voor Schimmelcultures (CBS-KNAW, Utrecht, The Netherlands) was used for all experiments. The yeast was grown in a $1000 \mathrm{~mL}$ Erlenmeyer flask containing a yeast malt broth (YMA) $\left(3 \mathrm{gL}^{-1}\right.$ yeast extract, $3 \mathrm{gL}^{-1}$ malt extract, $10 \mathrm{gL}^{-1}$ glucose and $5 \mathrm{~g} \mathrm{~L}^{-1}$ vegetable peptone) for 5 days at room temperature on a rotary shaker at $115 \mathrm{rpm}$. After 5 days, $15 \mathrm{~mL}$ of this media was used for inoculation of the wastewaters. The fermentation was carried out in $1000 \mathrm{~mL}$ Erlenmeyer flasks containing $500 \mathrm{~mL}$ of the respective wastewaters, which were cultivated under the same conditions as the initial YMA for $168 \mathrm{~h}$. For analysis of cell dry mass, lipid content and fatty acid composition $40 \mathrm{~mL}$ samples were taken regularly every $24 \mathrm{~h}$. For the analysis of carotenoid
TABLE 1: Initial chemical oxygen demand (COD), total nitrogen content $\left(N_{t}\right)$, and $\mathrm{pH}$ value measured in the collected wastewaters.

\begin{tabular}{lccc}
\hline Wastewater origin & $\begin{array}{c}\mathrm{COD} \\
\left(\mathrm{mg} \mathrm{L}^{-1}\right)\end{array}$ & $\begin{array}{c}\mathrm{N}_{t} \\
\left(\mathrm{mg} \mathrm{L}^{-1}\right)\end{array}$ & $\mathrm{pH}$ \\
\hline Potato processing & 13,200 & 210 & 7.10 \\
Fruit juice production & 1,068 & 10 & 8.18 \\
Lettuce processing & 885 & 30.5 & 7.98 \\
\hline
\end{tabular}

content and composition, $40 \mathrm{~mL}$ samples were taken at $t_{0 \mathrm{~h}}$, $t_{48 \mathrm{~h}}, t_{96 \mathrm{~h}}$, and $t_{120 \mathrm{~h}}$. From wastewater media from fruit juice and lettuce processing, additional samples were taken at $t_{168 \mathrm{~h}}$. The experiment was carried out in triplicate.

For determination of cell dry weight, the samples were centrifuged at $2750 \mathrm{rpm}$. The $\mathrm{pH}$ of the supernatant was determined, and the supernatant discarded afterwards. Cells were freeze-dried to constant weight. The cell mass was then measured using a calibrated balance.

The lipid content of the cellular material was determined using a modification of the method described by Bligh and Dyer [28]. Cells were disrupted using $12.5 \mathrm{~mL}$ methanol added to $5 \mathrm{~mL}$ aqueous mixture of water and cell material. Lipids were extracted with chloroform following the procedure described by Zhang et al. [29]. After $\mathrm{N}_{2}$ evaporation at $50^{\circ} \mathrm{C}$ for $60 \mathrm{~min}$, the weight of the extracted lipids was determined by a calibrated balance.

Afterwards the microbial lipids from sampling times $t_{0 \mathrm{~h}}, t_{48 \mathrm{~h}}$, and $t_{120 \mathrm{~h}}$ were transesterified to FAMEs to allow for chromatographic analysis of the fatty acid composition. Transesterification was carried out using methanol with 2\% $\mathrm{H}_{2} \mathrm{SO}_{4}$ as catalyst at $60^{\circ} \mathrm{C}$ for $2 \mathrm{~h}$. After quenching the reaction with $\mathrm{NaHCO}_{3}$ solution, the FAMEs were extracted by toluene and analyzed using an Agilent (Santa Clara, CA, USA) 6890 gas chromatograph with flame ionization detector (GC-FID) equipped with a Stabilwax-DA capillary column $(30 \mathrm{~m} \times 0.25 \mathrm{~mm}$ ID and $0.25 \mu \mathrm{m}$ film thickness). The different peaks were identified and quantified by comparison to responses from known FAME standards.

The samples for carotenoid analysis were centrifuged at $2750 \mathrm{rpm}$, freeze-dried, and hydrolysed with $1 \mathrm{~N} \mathrm{HCl}$ in a water bath at $70^{\circ} \mathrm{C}$ for $0.5 \mathrm{~h}$ [30]. The $\mathrm{HCl}$ solution containing the hydrolysed cells was filtered through a $0.7 \mu \mathrm{m}$ glass fiber filter. The filter paper with the residual cells was thoroughly rinsed with distilled water to remove the acid. The cells were extracted over the night in $35 \mathrm{~mL}$ acetone: methanol $(1: 1)$ solution. The acetone: methanol solvent was evaporated under $\mathrm{N}_{2}$ blow at $50^{\circ} \mathrm{C}$ for $60 \mathrm{~min}$, the extract then redissolved in $2 \mathrm{~mL}$ acetone, filtered, and prepared for HPLC analysis. For analysis, a Merck-Hitachi (Darmstadt, Germany) system was used, including interface module D-7000, pump L-7100, autosampler L-7200 and DAD detector L-7450A, and an Agilent (Böblingen, Germany) Eclipse Plus C18 column ( $5 \mu \mathrm{m} ; 250 \mathrm{~mm} \times 4,6 \mathrm{~mm})$. A gradient from 70 to $100 \%$ acetone was used as the mobile phase [31]. Chromatographic results were quantified by using response factor of $\beta$-carotene standards. Three distinct peaks were identified as compared to known retention time profiles 


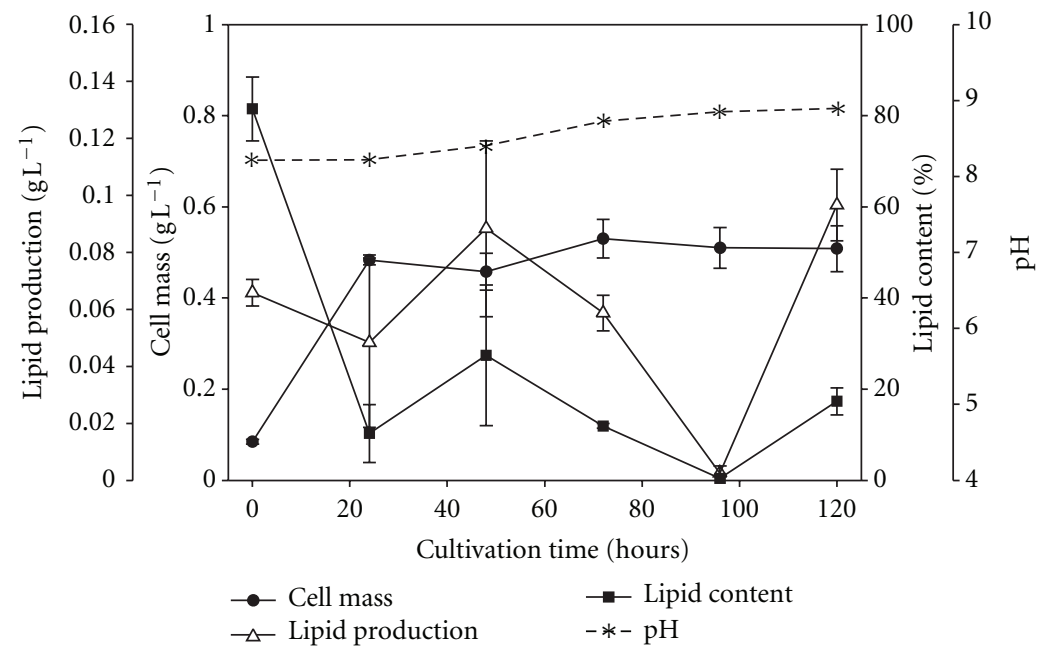

FIGURE 1: Cell mass production, lipid production, and lipid content of R. glutinis during cultivation on wastewaters from fruit juice processing.

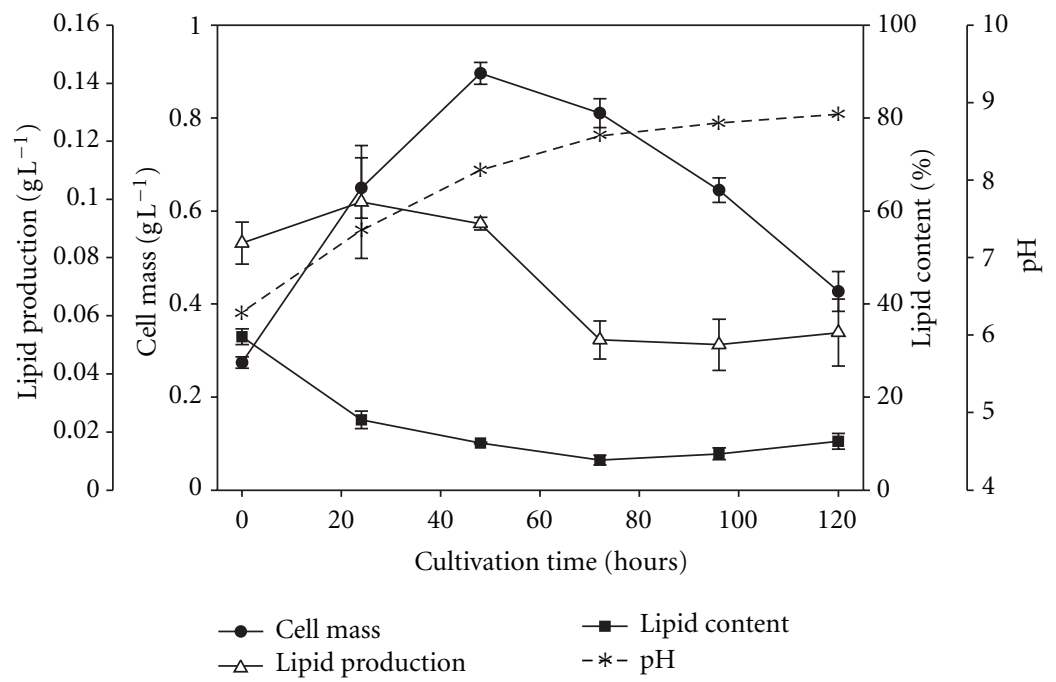

FIGURE 2: Cell mass production, lipid production, and lipid content of $R$. glutinis during cultivation on wastewaters from potato processing.

$[22,31]$. Amounts of the three peaks were summed to provide the total carotenoid content.

2.3. Statistical Analysis. All data was subject to statistical analysis using SigmaStat version 10.0 (Jandel Scientific, USA). The statistical significance of differences in mean values of cell mass, lipid production, and lipid content over the course of cultivation time was calculated using single factor variance analysis with the Tukey-Test at the 5\% level of probability.

\section{Results and Discussion}

3.1. Cell Growth of R. glutinis Grown in Wastewater Media. As shown on Figures 1-3, R. glutinis realized a significant increase in cell mass production on all wastewaters in the first hours of cultivation. Grown on the wastewater from fruit juice processing (Figure 1), cell mass rapidly increased sixfold from $0.08 \mathrm{~g} \mathrm{~L}^{-1}$ to $0.48 \mathrm{~g} \mathrm{~L}^{-1}$ during the first $24 \mathrm{~h}$ of cultivation and more or less stagnated for the remaining growth time with only slight but not significant increases to a maximum of $0.59 \mathrm{~g} \mathrm{~L}^{-1}$ at $96 \mathrm{~h}$. Wastewater from potato processing (Figure 2) also allowed for fast and significant cell growth until $48 \mathrm{~h}$ of cultivation, reaching a 3.5 higher weight $\left(0.91 \mathrm{~g} \mathrm{~L}^{-1}\right)$ compared to the initial cell mass $\left(0.26 \mathrm{~g} \mathrm{~L}^{-1}\right)$. After this peak, cell mass constantly decreased to a final value of $0.51 \mathrm{~g} \mathrm{~L}^{-1}$ at $t_{120}$. When grown on wastewater from lettuce processing (Figure 3), cell mass increased rather slowly from $0.11 \mathrm{~g} \mathrm{~L}^{-1}\left(t_{0}\right)$ to $0.31 \mathrm{~g} \mathrm{~L}^{-1}\left(t_{72}\right)$ until $t_{72}$ and stagnated after this. Due to different compounds in the wastewaters and possible differences in the cell mass of the inoculum, the initial cell mass concentration of the wastewaters was not the same for all three wastewaters. When compared on a relative 


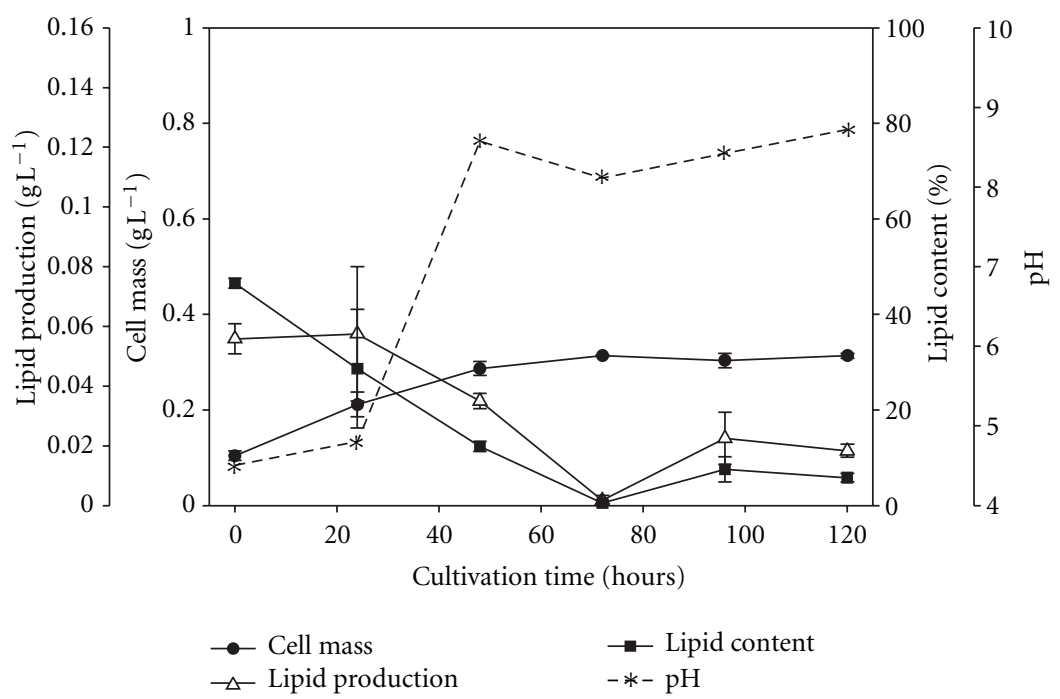

FIGURE 3: Cell mass production, lipid production, and lipid content of R. glutinis during cultivation on wastewaters from lettuce processing.

basis, $R$. glutinis realized the highest increase of cell mass on wastewaters from fruit juice processing. In this case, cell mass increased sixfold, whereas it only increased ca. threefold regarding wastewaters from potato and lettuce processing. These different patterns of cell growth are probably caused by the different levels and characteristics of the carbon sources available from the wastewaters. HPLC sugar analysis showed that fruit juice wastewaters contained small amounts of easily degradable glucose $\left(0.31 \mathrm{~g} \mathrm{~L}^{-1}\right)$ and xylose $\left(0.47 \mathrm{~g} \mathrm{~L}^{-1}\right)$, allowing for a quick and strong increase in cell mass during the first $24 \mathrm{~h}$ of cultivation. After this period, the carbon in the wastewater was exhausted leading to stagnation in cell growth. For wastewaters of potato and lettuce processing, HPLC analysis could not detect any glucose or xylose. Nevertheless, COD measurement showed that some organic but probably less degradable substances were present in the wastewaters, leading to lower and slower growth rates. This could also explain the similarity of relative growth rates realized on potato and lettuce processing wastewaters, despite the high difference in measured COD values.

\subsection{Lipid Production of R. glutinis Grown in Wastewater} Media. None of the wastewaters allowed for significant lipid production by $R$. glutinis. When grown on wastewaters from potato (Figure 2), lettuce (Figure 3), and fruit juice processing (Figure 1), the initial lipid content, the initial lipid content, which is explained by the lipid saturated cells of the inoculum, constantly decreased. The lipid content was calculated as ratio of cell mass and lipid production. Thus, in the first cultivation period, the decline in lipid content was probably mostly caused by the increase of cell production along with a stagnation in lipid production. On the contrary, during the second phase of cultivation, cell production stagnated while the lipid production decreased.

Oleaginous microorganisms start to produce lipids when a growth required nutrient, mostly nitrogen, is exhausted in the medium $[1,7]$. The excess carbon is then channeled into lipid production. Accordingly, it has been shown that the lipid content is constantly low when nitrogen is present in the culture medium [32]. Thus, the carbon to nitrogen ratio $(\mathrm{C} / \mathrm{N}$ ratio) of the culture medium is a very important parameter for the potential lipid production. As shown in Table 1, wastewaters from fruit juice and lettuce processing contain only a small amount of carbon as reflected by the low COD value. With comparatively low total nitrogen content of $10 \mathrm{mg} \mathrm{L}^{-1}$, it can be assumed that the fruit juice wastewater has a beneficially high $\mathrm{C} / \mathrm{N}$ ratio. Wastewater from lettuce processing showed a lower COD combined with a higher nitrogen content therefore indicating a lower $\mathrm{C} / \mathrm{N}$ ratio. However, the increases in cell mass in Figures 1 and 3 suggest that nitrogen was still available and the carbon sources were used in favor to cell production. The stagnation of cell growth along with the low lipid production indicated that most of the available carbon was exhausted before nitrogen became the growth limiting factor. The wastewater from potato processing is characterized by a relatively high COD value (Table 1). However, with simultaneously high total nitrogen content, this leads to an unfavorable $\mathrm{C} / \mathrm{N}$ ratio, which probably hindered lipid production. Also, here, it can be assumed that the carbon in the media was consumed before nitrogen was exhausted. Under favorable conditions regarding carbon and nitrogen content, $R$. glutinis was observed to display an $S$-shaped growth curve including a lag phase followed by an exponential phase and a stationary phase $[18,29]$. In this context, Xue at al. [18] suggest an initial COD concentration of over $30,000 \mathrm{mg} \mathrm{L}^{-1}$ to allow for lipid production which indicates that the COD of all chosen wastewaters in this experiment was to low to facilitate the classical course of lipid production.

As described by Papanikolaou and Aggelis [7], previously stored lipids are to some extent degraded to generate lipidfree material (lipid turnover) when the carbon sources in the fermentation medium are completely exhausted. The same observation could be made in this study, since lipid content 
further decreased after cell growth stagnated. The variability of lipid production in Figure 1 can be explained by the various anabolic and especially catabolic processes during cultivation. In the course of cell death and cell decay, new carbon sources are released into the media to some extent. In addition, the fluctuations of data for lipid production are ranging on a very low scale between 0 and $0.1 \mathrm{~g} \mathrm{~L}^{-1}$ and are also characterized by a high variance as reflected by the standard error.

The $\mathrm{pH}$ value is also an important factor influencing lipid production. Ranging between $\mathrm{pH} 7$ and $\mathrm{pH} 8$ (Table 1), all wastewaters were slightly alkaline. Since the medium was not buffered, the $\mathrm{pH}$ further increased in the course of cultivation. This could be due to organic acids being consumed from the medium. Since the optimum $\mathrm{pH}$ values for lipid accumulation of yeast cells were reported to be between $\mathrm{pH} 5.0$ and 6.0 [14], the high $\mathrm{pH}$ value of the wastewaters could be another limiting factor for lipid production. In subsequent experiments, the impact of $\mathrm{pH}$ adjustment and $\mathrm{pH}$ buffering during cultivation through the addition of alkaline $(\mathrm{NaOH})$ and acidic $(\mathrm{HCl})$ solutions should be investigated.

However, the most important limiting factors for lipid production in the screened wastewaters seem to be the low content of available carbon sources in fruit juice and lettuce processing waters and the high content of nitrogen in potato processing waters, respectively. Potential options to overcome these inhibitory factors could be the supplementation with additional carbon sources (e.g., monosaccharide) in order to increase the carbon content on the one hand or the reduction of nitrogen content on the other hand. However, it has to be carefully assessed if these actions would still be consistent with the premise of economic feasibility. Likewise, the screening of feedstocks has to be extended to other wastewaters like wastewaters from vegetable processing (especially blanching water), sugar refining, and beer production. Even though lipid production and lipid content were low, all wastewaters met the general criteria for microbial oil production. There was no evidence for the existence of any inhibitory wastewater components found.

Regarding the aspect of economic viability, it is difficult to determine a certain minimum necessary lipid production target, since this is strongly influenced by the substrate and the cost of the selected process to convert the oleaginous microorganisms into biodiesel. Mondala et al. [33] calculated for their work with activated sewage sludge that a lipid content of approximately $10 \%(\mathrm{wt} / \mathrm{wt})$ is necessary to produce biodiesel at a break-even price of approximately $\$ 3.20$ per gallon. This price would be economically competitive with that of petroleum-based diesel which is around $\$ 3.82$ per gallon (US Energy Information Administration, January, 2012) and with that of conventionally produced biodiesel (B 100 ) which is around $\$ 4,18$ per gallon (US Department of Energy, October 2011).

According to Revellame et al. [34], a biodiesel yield of more than $10 \%$ (wt/wt) will make the utilized feedstock cheaper than petroleum-based diesel (Figure 4). While in latter papers, the process of in situ transesterification was taken

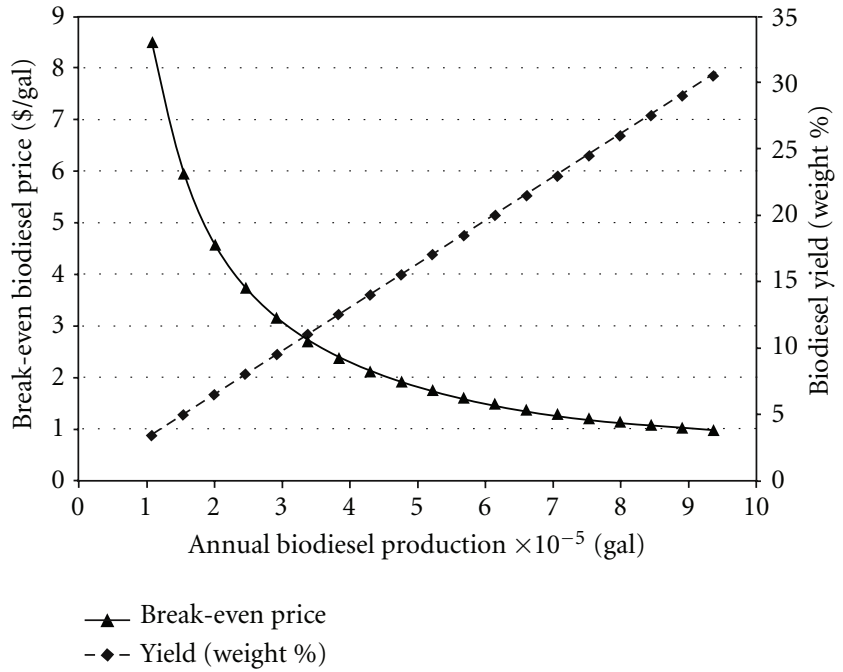

FIGURE 4: Influence of yield on the break-even price of biodiesel from wet activated sludge [34].

as the basis for calculation, this study uses the conventional process of drying, oil extraction, and conversion. Accordingly, it is difficult to apply these results to the approach described in this paper. Nevertheless, looking at the obtained results in this study, the lipid production needs to be significantly increased in order to reach a financially viable stage, even if the carotenoids as high value by-products are taken into consideration.

3.3. Fatty Acid Composition of Microbial Oils Produced in Wastewater Media. The gas chromatographic analysis of the FAMEs from microbial lipid showed a significant increase in the FAME content in the first 48 hours of cultivation for all three wastewaters (data not shown). The FAME composition, shown exemplary for sampling time $t_{48}$ in Figure 5 , also varied in the course of cultivation, whereas it was always predominated by long chain C 16 and C 18 fatty acid methyl esters, with oleic (C 18:1) and palmitic (C 16:0) acid methyl ester being the most important. This makes the properties of the microbial lipid comparable to plant oil, which mainly consists of palmitic and oleic acid [35]. Especially when wastewater form fruit juice and lettuce processing was used as growth substrate, linoleic (C $18: 2$ ) acid methyl ester was a main component of the overall FAME content as well. This is in accordance with Papanikolaou and Aggelis [7], who state that yeast lipid, which was produced utilizing sugar-based substrates, is generally composed of C 16 and C 18 fatty acids, while oleic acid (C 18:1) is the principal fatty acid followed by linoleic (C 18:2) and palmitic (C 16:0) acid. For the specific strain of R. glutinis (CBS 20) used in the present study, this fatty acid profile has been confirmed as well [36]. When grown on wastewaters from potato processing, the FAME composition also exhibited a high percentage of palmitoleic (C 16:1) and stearic (C 18:0) acid methyl esters (Figure 5).

3.4. Carotenoid Production of R. glutinis Grown in Wastewater Media. The total carotenoid production per Liter of 


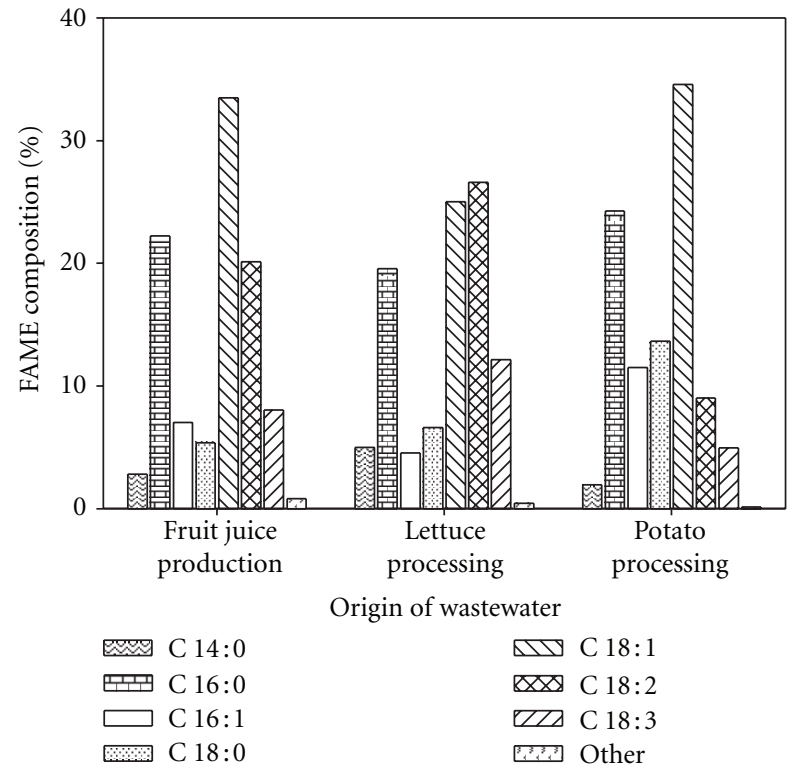

FIGURE 5: FAME composition of transesterified microbial lipid after 48 hours of cultivation with $R$. glutinis on different wastewaters.

wastewater in course of cultivation as displayed in Figure 6 showed great similarities for growth on wastewater media from fruit juice and lettuce processing. Grown on fruit juice wastewater media, R. glutinis realized a significant increase of almost $50 \%$ from $0.15 \mathrm{mg} \mathrm{L}^{-1}$ to $0.22 \mathrm{mg} \mathrm{L}^{-1}$ within the first $96 \mathrm{~h}$ of cultivation. Grown on lettuce wastewater the relative increase was $66 \%$ from $0.11 \mathrm{mg} \mathrm{L}^{-1}$ to $0.18 \mathrm{mg} \mathrm{L}^{-1}$ within the first $48 \mathrm{~h}$. The increases were followed by a stagnation of carotenoid production for both wastewaters. On the contrary, the results from cultures grown on potato processing wastewater displayed a decrease of carotenoid production in the first 48 hours, followed by stagnation at around $0.13 \mathrm{mg} \mathrm{L}^{-1}$. Yet, the differences in total carotenoid production were not at a significant level. Regarding the carotenoid composition, the wastewaters varied slightly from each other at the inoculation time $t_{0}$. After $48 \mathrm{~h}$ of cultivation, the shares of the different carotenoids remained at constant proportions.

Again the similarities between wastewaters from fruit juice production (32\% $\beta$-carotene, 39\% torulene, 29\% torularhodin) and lettuce processing (33\% $\beta$-carotene, $42 \%$ torulene, $25 \%$ torularhodin) could be observed, while results from potato processing wastewaters ( $43 \% \beta$-carotene, $13 \%$ torulene, $44 \%$ torularhodin) differed.

In consideration of the initially measured wastewater properties COD, total $N$, and $\mathrm{pH}$ (Table 1 ), it is difficult to evaluate these results, since the particular influence of these parameters on carotenoid production on $R$. glutinis has not been fully investigated yet. Of course the availability of a carbon source is a prerequisite for all metabolic processes. Thus, the limited amount of carbon in fruit juice and lettuce processing wastewaters probably caused the early stagnation of carotenoid production and the associated comparatively low level of carotenoid content. Accordingly as already stated for

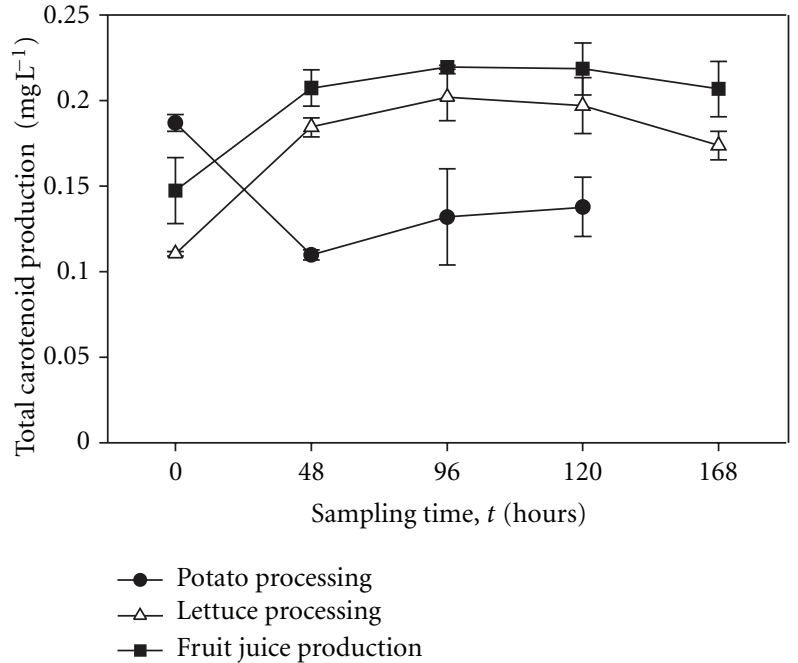

FIGURE 6: Total carotenoid production of $R$. glutinis during cultivation on wastewaters from potato, lettuce, and fruit juice processing.

lipid production, the tested wastewaters have to be improved if they should serve as medium for lipid and carotenoid production. However, although both lipid and carotenoid biosynthesis have the same precursor [37], results cited in literature are somewhat ambiguous when it comes to the influence of carbon and nitrogen source and the related $\mathrm{C} / \mathrm{N}$ ratio on carotenoid production. While some authors $[37,38]$ report an enhancement in carotenoid production with increasing $\mathrm{C} / \mathrm{N}$ ratio, others [39] found the opposite. Tinoi et al. [40] found that both increases in nitrogen and carbon source led to an increase in carotenoid content. The interactions between carbon and nitrogen source could also help to explain the drop of carotenoid production when grown on potato processing wastewaters. Based on the COD value, it can be suggested that carbon was available in sufficient quantities. Thus, it was probably the amount of nitrogen which influenced the carotenoid production or other substances in the wastewater that hindered carotenoid formation. Also, the relatively high $\mathrm{pH}$ value of the wastewaters could be a reason for the poor carotenoid production, since the optimum is reported to be around pH 6 [40]. Accordingly, it needs to be further investigated how carbon and nitrogen contents are related to carotenoid production before wastewaters can be effectively amended or specifically screened regarding their carbon and nitrogen content. If lipid and carotenoid production should be combined, it also needs to be considered that the optimization of process parameters and wastewater properties for the improvement of lipid yield will most likely be at the expense of carotenoid yield and vice versa.

\section{Conclusion}

All wastewaters showed the essential properties, which are mainly the presence of a degradable carbon source and the absence of any inhibitory substances, to allow for growth and second metabolism production of $R$. glutinis for the production of biodiesel and high-value pigments. Nevertheless, lipid 
production was very low and lipid turnover processes already started in early stages of cultivation time. This indicated that the amount of degradable carbon in the wastewaters was too low, especially in wastewaters from fruit juice and lettuce processing, using all carbon for cell proliferation processes at the onset of cultivation when nitrogen was still available. Also, in the case of potato processing wastewater, where the COD and accordingly the carbon content was expected to be comparably higher, no significant lipid production was observed, probably owing to the high nitrogen content. Thus, if lipid production should be enhanced, the wastewater properties have to be modified regarding their carbon and nitrogen content, respectively. This could be achieved by the supplementation with additional low-cost carbon sources (e.g., biomass hydrolysates) or the removal of nitrogen through chemical or biological measures but yet needs to be in accordance with the aim of financial viability. Also, the reduction of initial $\mathrm{pH}$ and buffering of the $\mathrm{pH}$ during cultivation could be a way to enhance lipid and carotenoid production. The production of carotenoids was quantitatively confirmed, showing the general compatibility of lipid and carotenoid production. However, the influence of carbon and nitrogen content on carotenoid production needs to be further investigated in order to optimize both lipid and carotenoid production. For economic feasibility, lipid and carotenoid production needs to be increased significantly. Likewise, the screening of wastewaters should be extended with additional promising wastewaters like wastewaters from sugar refining, vegetable processing (i.e., blanching water), or beer production.

\section{References}

[1] P. S. Nigam and A. Singh, "Production of liquid biofuels from renewable resources," Progress in Energy and Combustion Science, vol. 37, no. 1, pp. 52-68, 2011.

[2] B. Liu and Z. Zhao, "Biodiesel production by direct methanolysis of oleaginous microbial biomass," Journal of Chemical Technology and Biotechnology, vol. 82, no. 8, pp. 775-780, 2007.

[3] R. Subramaniam, S. Dufreche, M. Zappi, and R. Bajpai, "Microbial lipids from renewable resources: production and characterization," Journal of Industrial Microbiology and Biotechnology, vol. 37, no. 12, pp. 1271-1287, 2010.

[4] C. Ratledge, "Microorganisms for lipids," Acta Biotechnologica, vol. 11, no. 5, pp. 429-438, 1991.

[5] J. M. Ageitos, J. A. Vallejo, P. Veiga-Crespo, and T. G. Villa, "Oily yeasts as oleaginous cell factories," Applied Microbiology and Biotechnology, vol. 90, no. 4, pp. 1219-1227, 2011.

[6] Q. Li, W. Du, and D. Liu, "Perspectives of microbial oils for biodiesel production," Applied Microbiology and Biotechnology, vol. 80, no. 5, pp. 749-756, 2008.

[7] S. Papanikolaou and G. Aggelis, "Lipids of oleaginous yeast. Part I. Biochemistry related with single cell oil production," Journal of Lipid Science and Technology, vol. 113, no. 8, pp. 1031-1051, 2011.

[8] B. Cheirsilp, W. Suwannarat, and R. Niyomdecha, "Mixed culture of oleaginous yeast Rhodotorula glutinis and microalga Chlorella vulgaris for lipid production from industrial wastes and its use as biodiesel feedstock," New Biotechnology, vol. 28, no. 4, pp. 362-368, 2011.
[9] P. Akhtar, J. I. Gray, and A. Asghar, "Synthesis of lipids by certain yeast strains grown on whey permeate," Journal of Food Lipids, vol. 5, no. 4, pp. 283-297, 1998.

[10] Z. Chi, Y. Zheng, A. Jiang, and S. Chen, "Lipid production by culturing oleaginous yeast and algae with food waste and municipal wastewater in an integrated process," Applied Biochemistry and Biotechnology, vol. 165, no. 2, pp. 442-453, 2011.

[11] J. Hall, M. Hetrick, T. French et al., "Oil production by a consortium of oleaginous microorganisms grown on primary effluent wastewater," Journal of Chemical Technology and Biotechnology, vol. 86, no. 1, pp. 54-60, 2011.

[12] C. Angerbauer, M. Siebenhofer, M. Mittelbach, and G. M. Guebitz, "Conversion of sewage sludge into lipids by Lipomyces starkeyi for biodiesel production," Bioresource Technology, vol. 99, no. 8, pp. 3051-3056, 2008.

[13] C. Hu, X. Zhao, J. Zhao, S. Wu, and Z. K. Zhao, "Effects of biomass hydrolysis by-products on oleaginous yeast Rhodosporidium toruloides," Bioresource Technology, vol. 100, no. 20, pp. 4843-4847, 2009.

[14] S. E. Karatay and G. Dönmez, "Improving the lipid accumulation properties of the yeast cells for biodiesel production using molasses," Bioresource Technology, vol. 101, no. 20, pp. 79887990, 2010.

[15] H. A. El-Fadaly, N. E. A. El-Naggar, and E. S. M. Marwan, "Single cell oil production by an oleaginous yeast strain in a low cost cultivation medium," Research Journal of Microbiology, vol. 4, no. 8, pp. 301-313, 2009.

[16] R. M. Alvarez, B. Rodríguez, J. M. Romano et al., "Lipid accumulation in Rhodotorula glutinis on sugar cane molasses in single-stage continuous culture," World Journal of Microbiology \& Biotechnology, vol. 8, no. 2, pp. 214-215, 1992.

[17] E. R. Easterling, W. T. French, R. Hernandez, and M. Licha, "The effect of glycerol as a sole and secondary substrate on the growth and fatty acid composition of Rhodotorula glutinis," Bioresource Technology, vol. 100, no. 1, pp. 356-361, 2009.

[18] F. Xue, B. Gao, Y. Zhu, X. Zhang, W. Feng, and T. Tan, "Pilotscale production of microbial lipid using starch wastewater as raw material," Bioresource Technology, vol. 101, no. 15, pp. 6092-6095, 2010.

[19] X. Meng, J. Yang, X. Xu, L. Zhang, Q. Nie, and M. Xian, "Biodiesel production from oleaginous microorganisms," Renewable Energy, vol. 34, no. 1, pp. 1-5, 2009.

[20] J. G. Pan, M. Y. Kwak, and J. S. Rhee, "High density cell culture of Rhodotorulaglutinis using oxygen-enriched air," Biotechnology Letters, vol. 8, no. 10, pp. 715-718, 1986.

[21] S. Misra, A. Ghosh, and J. Dutta, "Production and composition of microbial fat from Rhodotorula glutinis," Journal of the Science of Food and Agriculture, vol. 35, no. 1, pp. 59-65, 1984.

[22] P. Buzzini, M. Innocenti, B. Turchetti, D. Libkind, M. van Broock, and N. Mulinacci, "Carotenoid profiles of yeasts belonging to the genera Rhodotorula, Rhodosporidium, Sporobolomyces, and Sporidiobolus," Canadian Journal of Microbiology, vol. 53, no. 8, pp. 1024-1031, 2007.

[23] B. D. Ribeiro, D. W. Barreto, and M. A.Z. Coelho, "Technological aspects of $\beta$-carotene production," Food and Bioprocess Technology, vol. 4, no. 5, pp. 693-701, 2011.

[24] C. Malisorn and W. Suntornsuk, "Optimization of $\beta$-carotene production by Rhodotorula glutinis DM28 in fermented radish brine," Bioresource Technology, vol. 99, no. 7, pp. 2281-2287, 2008.

[25] G. Frengova, E. Simova, K. Pavlova, B. Beshkova, and D. Grigorova, "Formation of carotenoids by Rhodotorula glutinis in whey ultrafiltrate," Biotechnology and Bioengineering, vol. 44, no. 8, pp. 888-894, 1994. 
[26] P. Buzzini and A. Martini, "Production of carotenoids by strains of Rhodotorula glutinis cultured in raw materials of agro-industrial origin,” Bioresource Technology, vol. 71, no. 1, pp. 41-44, 2000.

[27] G. Frengova and D. Beshkova, "Carotenoids from Rhodotorula and Phaffia: yeasts of biotechnological importance," Journal of Industrial Microbiology and Biotechnology, vol. 36, no. 2, pp. 163-180, 2009.

[28] E. G. Bligh and W. J. Dyer, "A rapid method of total lipid extraction and purification," Canadian Journal of Biochemistry and Physiology, vol. 37, no. 8, pp. 911-917, 1959.

[29] G. Zhang, W. T. French, R. Hernandez, E. Alley, and M. Paraschivescu, "Effects of furfural and acetic acid on growth and lipid production from glucose and xylose by Rhodotorula glutinis," Biomass and Bioenergy, vol. 35, no. 1, pp. 734-740, 2011.

[30] B. V. Latha, K. Jeevaratnam, H. S. Murali, and K. S. Manja, "Influence of growth factors on carotenoid pigmentation of Rhodotorula glutinis DFR-PDY from natural source," Indian Journal of Biotechnology, vol. 4, no. 3, pp. 353-357, 2005.

[31] R. W. S. Weber, H. Anke, and P. Davoli, "Simple method for the extraction and reversed-phase high-performance liquid chromatographic analysis of carotenoid pigments from red yeasts (Basidiomycota, Fungi)," Journal of Chromatography A, vol. 1145, no. 1-2, pp. 118-122, 2007.

[32] L. M. Granger, P. Perlot, G. Goma, and A. Pareilleux, "Effect of various nutrient limitations on fatty acid production by Rhodotorula glutinis," Applied Microbiology and Biotechnology, vol. 38, no. 6, pp. 784-789, 1993.

[33] A. Mondala, K. Liang, H. Toghiani, R. Hernandez, and T. French, "Biodiesel production by in situ transesterification of municipal primary and secondary sludges," Bioresource Technology, vol. 100, no. 3, pp. 1203-1210, 2009.

[34] E. Revellame, R. Hernandez, W. French, W. Holmes, E. Alley, and R. Callahan, "Production of biodiesel from wet activated sludge," Journal of Chemical Technology and Biotechnology, vol. 86, no. 1, pp. 61-68, 2011.

[35] M. M. Gui, K. T. Lee, and S. Bhatia, "Feasibility of edible oil vs. non-edible oil vs. waste edible oil as biodiesel feedstock," Energy, vol. 33, no. 11, pp. 1646-1653, 2008.

[36] V. Perrier, E. Dubreucq, and P. Galzy, "Fatty acid and carotenoid composition of Rhodotorula strains," Archives of Microbiology, vol. 164, no. 3, pp. 173-179, 1995.

[37] P. K. Park, D. H. Cho, E. Y. Kim, and K. H. Chu, “Optimization of carotenoid production by Rhodotorula glutinis using statistical experimental design," World Journal of Microbiology and Biotechnology, vol. 21, no. 4, pp. 429-434, 2005.

[38] C. Saenge, B. Cheirsilp, T. T. Suksaroge, and T. Bourtoom, "Potential use of oleaginous red yeast Rhodotorula glutinis for the bioconversion of crude glycerol from biodiesel plant to lipids and carotenoids," Process Biochemistry, vol. 46, no. 1, pp. 210-218, 2011.

[39] D. Somashekar and R. Joseph, "Inverse relationship between carotenoid and lipid formation in Rhodotorula gracilis according to the $\mathrm{C} / \mathrm{N}$ ratio of the growth medium," World Journal of Microbiology and Biotechnology, vol. 16, no. 5, pp. 491-493, 2000.

[40] J. Tinoi, N. Rakariyatham, and R. L. Deming, "Simplex optimization of carotenoid production by Rhodotorula glutinis using hydrolyzed mung bean waste flour as substrate," Process Biochemistry, vol. 40, no. 7, pp. 2551-2557, 2005. 

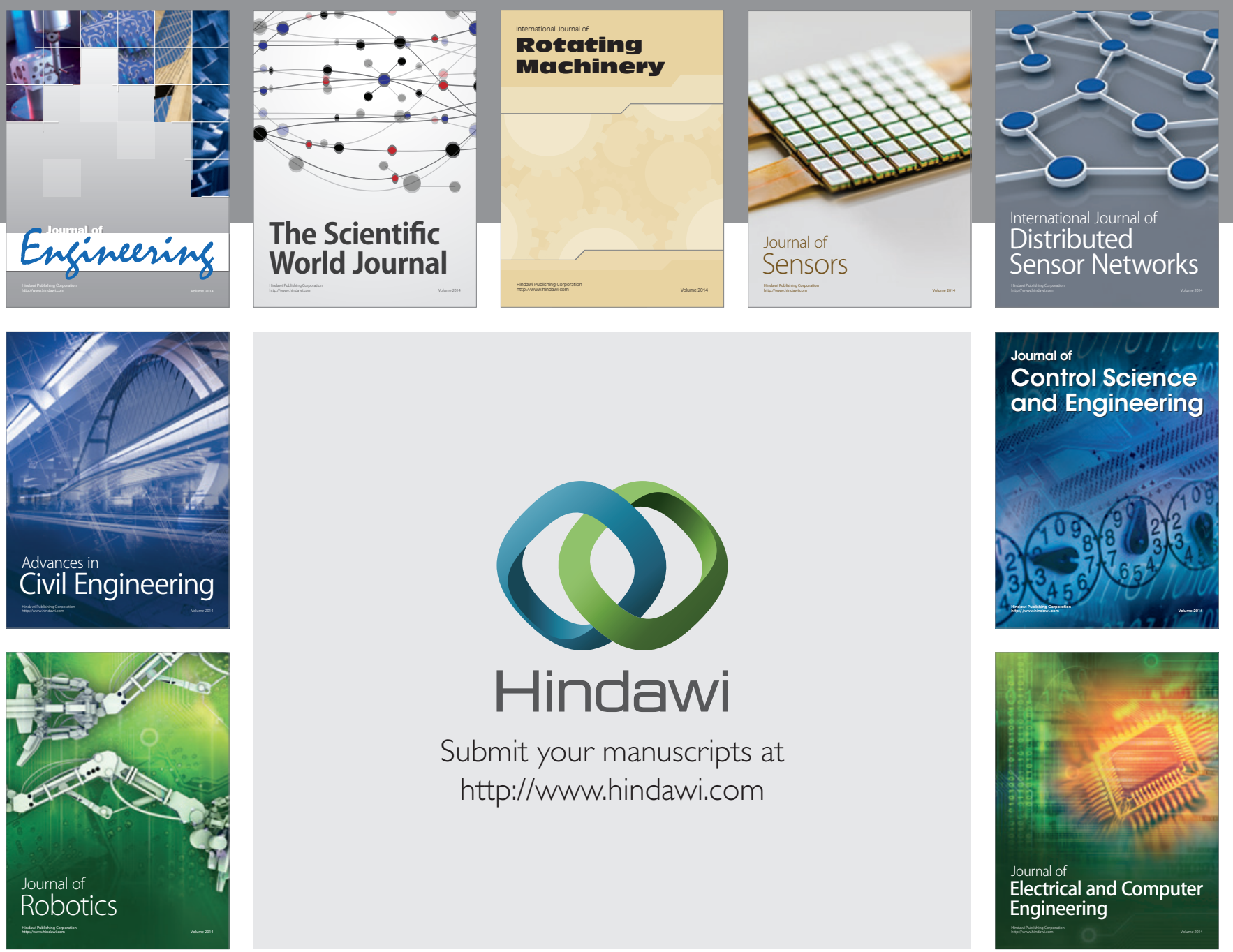

Submit your manuscripts at

http://www.hindawi.com
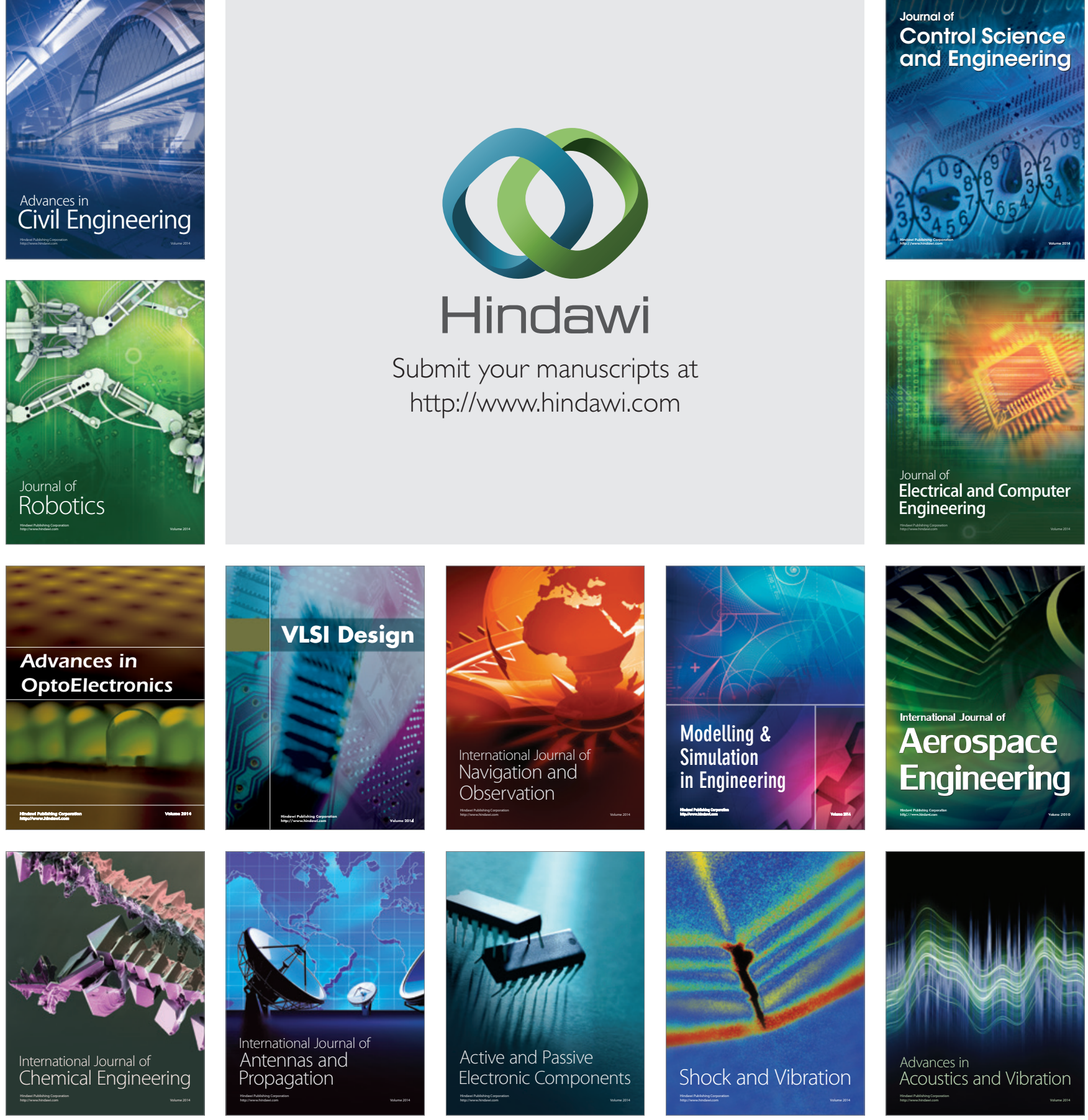